Research article

\title{
Sorption of radioactive cesium and barium ions onto solid humic acid
}

\author{
O. Celebi ${ }^{\mathrm{a}, *}$, A. Kilikli ${ }^{\mathrm{b}}$, H.N. Erten ${ }^{\mathrm{c}}$ \\ a Department of Chemistry, Macromolecular Science and Engineering, Virginia Tech, Blacksburg, VA 24061, USA \\ b Department of Chemistry, Middle East Technical University, 06530 Ankara, Turkey \\ c Department of Chemistry, Bilkent University, 06800 Bilkent, Ankara, Turkey
}

\section{A R T I C L E I N F O}

\section{Article history:}

Received 21 June 2008

Received in revised form

24 November 2008

Accepted 17 February 2009

Available online 25 February 2009

\section{Keywords:}

Humic acid

Adsorption

Radioactive substances

Radiotracer method

Thermodynamic parameters

\begin{abstract}
A B S T R A C T
In this study, the sorption behavior of two important fission product radionuclides ( ${ }^{137} \mathrm{Cs}$ and $\left.{ }^{140} \mathrm{Ba}\right)$ onto sodium form of insolubilized humic acid (INaA) were investigated as a function of time, cation concentration and temperature, utilizing the radiotracer method. The sorption processes are well described by both Freundlich and Dubinin-Radushkevich type isotherms. Thermodynamic constants such as; free energy ( $\Delta G_{\text {ads }}$ ), enthalpy $\left(\Delta H_{\text {ads }}\right)$, entropy $\left(\Delta S_{\text {ads }}\right)$ of adsorption were determined. It was found that $\mathrm{Ba}^{2+}$ was adsorbed five times more than $\mathrm{Cs}^{+}$onto structurally modified humic acid and kinetic studies indicated that adsorption behavior of both ions obey the pseudo second order rate law. The effect of $\mathrm{pH}$ change on sorption was also examined. FTIR and solid-state carbon NMR ( $\left.{ }^{13} \mathrm{CNMR}\right)$ spectroscopic techniques were used to understand the structural changes during insolubilization process. Quantitative determination of adsorption sites was carried out using potantiometric titration.
\end{abstract}

(C) 2009 Elsevier B.V. All rights reserved.

\section{Introduction}

There is an increasing effort for removing highly soluble radiocontaminants from aqueous waste solutions by fixing them onto solid waste forms that can be disposed of in a repository. The radionuclide ${ }^{137} \mathrm{Cs}$ is produced in high yield during the fission process and due to its long half-life $\left(T_{1 / 2}=30.17 \mathrm{yr}\right)$ and its high solubility in aqueous media, it is a principal radiocontaminant in radioactive wastes [1,2].

Barium is an alkaline earth element $(Z=56)$, its radioactive isotope ${ }^{140} \mathrm{Ba}\left(T_{1 / 2}=12.79\right.$ days $)$ is a fission product with a high yield (6.21\%). This radionuclide is a serious radiocontaminant, furthermore being a homologue of $\mathrm{Ra}, \mathrm{Ba}^{2+}$ is a suitable cation for the radiochemical study of $\mathrm{Ra}^{2+}$, which has several radioisotopes that are important in radioactive waste considerations. ${ }^{133} \mathrm{Ba}^{2+}$ was chosen as a radiotracer in our studies because of its long half-life $\left(T_{1 / 2}=10.7 \mathrm{yr}\right)$ and a $\gamma$-ray at $356 \mathrm{keV}$ energy [3].

Humic substances (HSs) are an abundant reservoir of carbon on earth. Humic acids (HAs) are operationally defined as the fraction of HS that is insoluble in water at low $\mathrm{pH}(<2)$. HA perform various roles in soil chemistry. They act as soil stabilizers, nutrients and water reservoirs for plants, sorbents for toxic metal ions, radionuclides and organic pollutants. When leached into surface waters, they also play a pivotal role in the aquatic environment.

\footnotetext{
* Corresponding author. Tel.: +1 540 5589586; fax: +1 5402318517.

E-mail address: celebi@vt.edu (O.Celebi).
}

For example, they bind and transport metal ions. Early concepts, based on the developing field of polymer science assumed that humic substances comprised of randomly coiled macromolecules that had elongated shapes in basic or low-ionic strength solutions, but became coils in acidic or high-ionic strength solutions. However, recent information gathered using spectroscopic, microscopic, pyrolysis, and soft ionization techniques is not consistent with the polymer model of humic substances. A new concept of humic substances has thus emerged, that of the supramolecular association, in which many relatively small and chemically diverse organic molecules form clusters linked by hydrogen bonds and hydrophobic interactions. A corollary to this model is the concept of micellar structure, i.e., an arrangement of organic molecules in aqueous solution to form hydrophilic exterior regions shielding hydrophobic interiors from contact with vicinal water molecules [4].

Generally, humic acid is soluble above $\mathrm{pH} 2.0$ in aqueous media and this makes humic acid inappropriate for traditional operations such as adsorption and recovery of metal ions. The solubility of humic acid depends on the number of $-\mathrm{COOH}$ and $-\mathrm{OH}$ groups present. These groups also give humic acid the ability to interact with metal ions through adsorption, ion-exchange, and complexation mechanisms. However, the high solubility of humic acid is a limiting problem. Accordingly, an appropriate treatment of humic acid is required [5]. The process developed by Seki and Suzuki [6] is called "insolubilization of humic acid" and with this method humic acid can be converted to a form which is insoluble up to $\mathrm{pH} 10$ in aqueous media. 
A number of articles have been published in the field of adsorption of cations onto insolubilized humic acid (IHA) [7]. Gezici et al. [5] reported the sorption behavior of a nickel-insolubilized humic acid system in a column arrangement. In another study Baker and Khalili [8] examined the analysis of the removal of lead(II) from aqueous solutions by adsorption onto insolubilized humic acid. ElEswed and Khalili [9] reported the adsorption of $\mathrm{Cu}$ (II) and $\mathrm{Ni}(\mathrm{II})$ on solid humic acid.

In this study, the adsorption behavior of the fission product radionuclides ${ }^{137} \mathrm{Cs}$ and ${ }^{140} \mathrm{Ba}$ onto insolubilized humic acid were investigated both kinetically and thermodynamically. The resulting data was analyzed using Freundlich and Dubinin-Radushkevich (D-R) isotherms. The structural changes during insolubilization process were determined by spectroscopic techniques and also quantitative determination of adsorption sites was carried out.

\section{Experimental}

\subsection{Chemicals}

All chemicals used were of analytical grade. Humic acid sample was taken from Nigde (Bor) region. Metal ion solutions were prepared by using only distilled water. No further ionic strength or $\mathrm{pH}$ control was attempted. The $\mathrm{pH}$ of the solutions in contact with insolubilized humic acid was 3.5.

\subsection{Isolation and insolubilization of humic acid}

Humic acid was isolated from soil sample by the following procedure; crude humic acid was stirred in $1 \% \mathrm{NaOH}$ solution for $1 \mathrm{~h}$ and subsequently centrifuged at $5000 \mathrm{rpm}$. The dissolved fraction was adjusted to $\mathrm{pH} 2$ with $\mathrm{HCl}$, stirred for $4 \mathrm{~h}$ and centrifuged at $5000 \mathrm{rpm}$. The resulting precipitate was taken and this procedure was repeated two more times. The precipitate was then rinsed with deionized water many times to remove chloride ions. After dechlorination, HA was dried at $95^{\circ} \mathrm{C}$ for $4 \mathrm{~h}$.

Humic acid was insolubilized by heating in a temperature controlled oven at $330^{\circ} \mathrm{C}$ for $1.5 \mathrm{~h}$ and solid, IHA, was converted to its sodium form (INaA) by stirring in a $1 \mathrm{M} \mathrm{NaNO}_{3}$ solution for 2 days. The resulting solid phase was dried at $80^{\circ} \mathrm{C}$. The solid phase was ground to powder and the particle size was $\leq 30 \mu \mathrm{m}$ in all experiments.

\subsection{Quantitative determination of adsorption sites on $H A$}

Adsorption sites (carboxylic and phenolic groups) were determined quantitatively by using potantiometric titration method. Model 5669-20 pH meter, Cole Parmer Instrument Company, was used for $\mathrm{pH}$ measurements. Titration was carried out from $\mathrm{pH}$ 3.5 to 10.58 using $0.1 \mathrm{M} \mathrm{NaOH}$ as titrant. Analyte was containing $50 \mathrm{ml}$ suspension of humic acid $\left(576 \mathrm{mgl}^{-1}\right)$. This concentration was also used by other studies [10]. Nitrogen gas was passed through the solution during titration in order to prevent $\mathrm{CO}_{2}$ interference. Resulting data was linearized by using the appropriate Gran functions [11]. The total acidity value was taken to be the sum of carboxylic and phenolic acidities.

\subsection{Adsorption experiments}

\subsubsection{Radiotracer method}

Batch method was used throughout the study. The tracers used in sorption experiments were ${ }^{137} \mathrm{Cs}\left(T_{1 / 2}=30.17 \mathrm{yr}\right)$ and ${ }^{133} \mathrm{Ba}$ $\left(T_{1 / 2}=10.7 \mathrm{yr}\right)$. 11 of stable isotope solutions were spiked with few microliters $(400 \mu \mathrm{l})$ of the corresponding radionuclide solutions. The initial count rates were measured in $2.5 \mathrm{ml}$ aliquots of cesium and barium solutions using the prominent $\gamma$-rays of 662 and $361 \mathrm{keV}$, respectively. Initial activities were adjusted not to be lower value than $10,000(\mathrm{cps}) / \mathrm{ml}$.

A NaI(Tl) detector was used during radioactivity measurements. All the experiments were performed in duplicate. Any loss in activity originating from adsorption on the tubes, was checked by blank experiments using solutions without adsorbent. Adsorption onto the tube walls was found to be negligible.

\subsubsection{Kinetic studies}

To each of a set of $5 \mathrm{~g} \mathrm{INaA}$ samples placed in tubes, $7.5 \mathrm{ml}$ of $\mathrm{Cs}^{+}$ and $\mathrm{Ba}^{2+}$ solution (prepared from $\mathrm{CsCl}$ and $\mathrm{BaCl}_{2}$ salts) containing an appropriate amount of ${ }^{137} \mathrm{Cs}$ and ${ }^{133} \mathrm{Ba}$ radiotracers was added. The initial $\mathrm{Cs}^{+}$and $\mathrm{Ba}^{2+}$ concentrations in solution was $1 \times 10^{-4} \mathrm{M}$. Samples were shaken at room temperature for periods ranging from $5 \mathrm{~min}$ to $48 \mathrm{~h}$.They were centrifuged at $5000 \mathrm{rpm}$ and $2.5 \mathrm{ml}$ portions of the liquid phases were counted.

\subsubsection{Effect of loading, temperature and $\mathrm{pH}$}

Loading experiments were carried out to investigate the effect of initial cation concentrations on sorption at four different temperatures; $15^{\circ} \mathrm{C}, 25^{\circ} \mathrm{C}, 35^{\circ} \mathrm{C}, 45^{\circ} \mathrm{C}$. The initial concentrations were $5 \times 10^{-4}, 1 \times 10^{-4}, 1 \times 10^{-5}, 5 \times 10^{-6}(\mathrm{mmol} / \mathrm{ml})$ for $\mathrm{Cs}^{+}$solutions. In the case of $\mathrm{Ba}^{2+}$ sorption the highest temperature was $55^{\circ} \mathrm{C}$ and concentrations used were $1 \times 10^{-4}, 1 \times 10^{-5}, 5 \times 10^{-6}$, $1 \times 10^{-6}(\mathrm{mmol} / \mathrm{ml})$. No other electrolytes were added. The effect of $\mathrm{pH}$ upon sorption of $\mathrm{Ba}^{2+}$ onto INaA was investigated at a fixed concentration $\left(1 \times 10^{-5} \mathrm{~mol} / \mathrm{l}\right)$ at room temperature. The $\mathrm{pH}$ range was from 1.5 to 10 . The samples were shaken for 1 day, centrifuged and $2.5 \mathrm{ml}$ of portions of the liquid phase were counted. For loading experiments shaking was done in a temperature controlled environment $\left( \pm 1^{\circ} \mathrm{C}\right)$ using a Nuve ST 402 water bath shaker equipped with microprocessor thermostat.

\subsection{Spectroscopic characterization of humic acid and insolubilized humic acid}

\subsubsection{FTIR}

FT-IR spectra were recorded using a Bruker Tensor 27 FTIR spectrometer with a standard high sensitivity DLATGS detector, with a resolution of $4 \mathrm{~cm}^{-1}$ and 64 scans, The $\mathrm{KBr}$ pellets were obtained by pressing a mixture of $1: 100$ ratio of humic samples and $\mathrm{KBr}$, respectively.

\subsection{2. ${ }^{13} \mathrm{C} N M R$}

Solid-state ${ }^{13} \mathrm{C}$ NMR spectra were obtained at the ${ }^{13} \mathrm{C}$ resonance frequency of $125.721 \mathrm{MHz}$ on a Bruker Avance ASX 500 spectrometer, equipped with a double resonance HX probe. The samples were confined in a zirconium oxide rotor with an external diameter of $2.5 \mathrm{~mm}$. The cross-polarization magic angle spinning CPMAS technique was applied with a contact time of $1 \mathrm{~ms}$, a spinning speed of $15 \mathrm{kHz}$ MAS and a pulse delay of $2 \mathrm{~s}$.

\section{Results and discussion}

\subsection{Potantiometric titration}

To quantify the acidic functional (carboxylic and phenolic) groups, potantiometric titration method was used. It is usual to plot the differential curves, $\Delta \mathrm{pH} / \Delta V$ or $\Delta E / \Delta V$ against volume of titrant added, but when the titration curve is not symmetrical close to the equivalence point, as in Fig. 1, then it is possible to obtain erroneous results. Therefore, Gran [11] developed a mathematical expressions to linearize titration curves. In our data treatment, we chose the following equation, assuming that humic acid is a polymeric acid and 


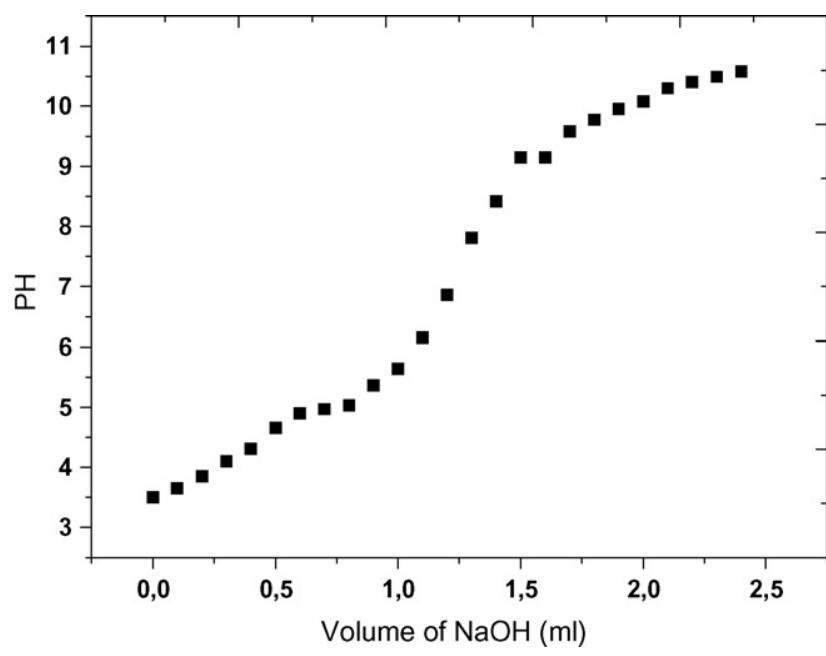

Fig. 1. Potantiometric titration curve of humic acid.

the titration type as weak acid-strong base titration.

$G=V \times 10^{\mathrm{pH}-k}$

where $V$ represents the amount of titrant used $(\mathrm{ml})$ and $k$ is an arbitrary constant with a value such that the antilogarithms will fall in a suitable range such as $0-100$.

After conversion of the potantiometric titration data to linearized form using Gran functions, two associated lines were obtained as shown in Fig. 2. The intersection point of the first line gives the amount of base needed to neutralize carboxylic acid groups and the second intersection point is the amount of total base which is required to neutralize all acidic functional groups. The difference is the amount of base which is required to neutralize phenolic groups. The following quantitative acidic functional group and total acidity values are obtained; carboxylic acidity, $249 \pm 25$ mequiv./100 g phenolic acidity, $190 \pm 19$ mequiv./100 g and total acidity value is $439 \pm 44$ mequiv./100 g.

\subsection{FTIR and ${ }^{13} C$ NMR spectra of humic acid and sodium form of insolubilized humic acid}

FTIR spectroscopy was used to examine the structural changes after insolubilization process. The peaks and corresponding functional groups in FTIR spectrum shown in Fig. 3 are as follows; a broad band at $3387 \mathrm{~cm}^{-1}$ primarily corresponds to $\mathrm{O}-\mathrm{H}$ stretching

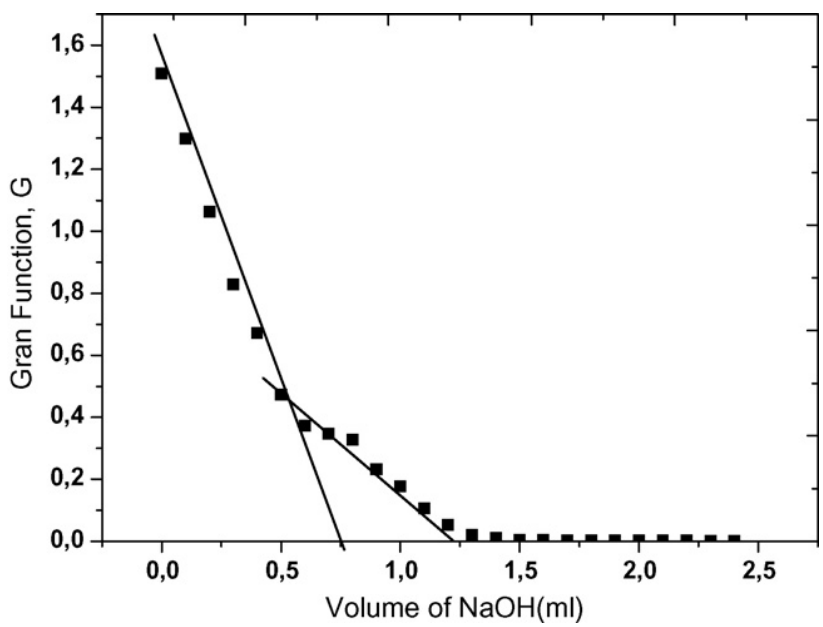

Fig. 2. Linearized plot potantiometric titration curve of humic acid.

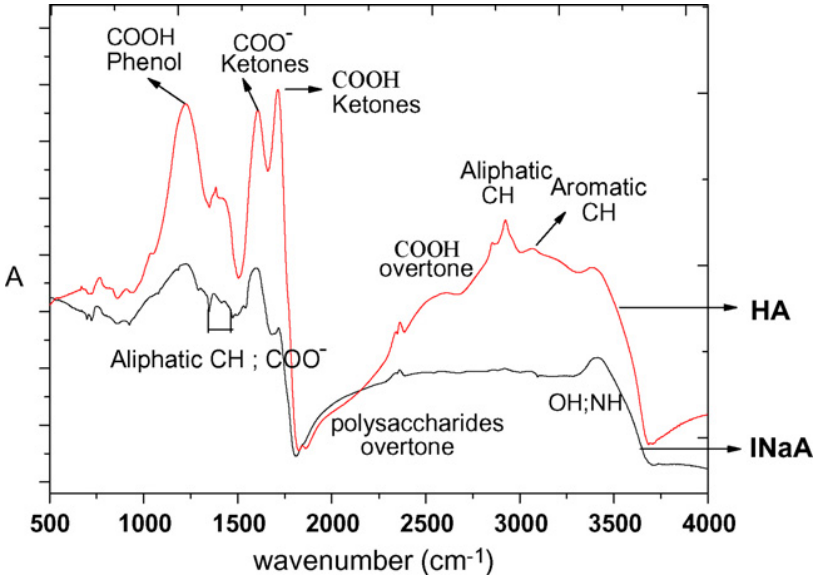

Fig. 3. FTIR spectra of humic acid and sodium form of insolubilized humic acid.

and secondarily to $\mathrm{N}-\mathrm{H}$ stretching, the peak at $3071 \mathrm{~cm}^{-1}$ represents stretching of aromatic $\mathrm{C}-\mathrm{H}$, absorption bands at 2928 and $2857 \mathrm{~cm}^{-1}$ are attributed to aliphatic $\mathrm{C}-\mathrm{H}$ stretching in $\mathrm{CH}_{2}$ and $\mathrm{CH}_{3}$, respectively.

Broad bands at $2500 \mathrm{~cm}^{-1}$ is overtone from carboxylic groups stretching $\left(2 \times 1246 \mathrm{~cm}^{-1}\right)$ and at $2000 \mathrm{~cm}^{-1}$ is overtone from C-O polysaccharides stretching mode $\left(2 \times 1060 \mathrm{~cm}^{-1}\right)$, strong absorption band at $1704 \mathrm{~cm}^{-1}$ is due to $\mathrm{C}=0$ stretching of carboxylic acid and ketone and absorption bands at $1602 \mathrm{~cm}^{-1}$ and $1372 \mathrm{~cm}^{-1}$ are ascribed to stretching of carboxylate ion and the peak at $1602 \mathrm{~cm}^{-1}$ can also be attributed to structural vibrations of aromatic $\mathrm{C}=\mathrm{C}$ bonds, the peak at $1222 \mathrm{~cm}^{-1}$ represents $\mathrm{C}-\mathrm{O}$ stretching in phenols and $\mathrm{O}-\mathrm{H}$ deformation of $\mathrm{COOH}$. The absorptions from deformation of aliphatic $\mathrm{C}-\mathrm{H}$ and, $\mathrm{H}$-bonded $\mathrm{C}=\mathrm{O}$ of conjugated ketones and water deformation occurs at $1448 \mathrm{~cm}^{-1}$, the band at $1033 \mathrm{~cm}^{-1}$ represents $\mathrm{C}-\mathrm{O}$ stretching of polysaccharides [12-14].

The ${ }^{13} \mathrm{C}$ spectra in Fig. 4 of $\mathrm{HA}$ and sodium form of insolubilized humic acid (INaA) include the following peaks: (a) alkyl carbons and $O$-alkyl carbons (aminoacids/carbons adjacent to ester/ether/hydroxyl) $(0-60 \mathrm{ppm})$. Because that peak was not well resolved we observe those two groups in a broad band; (110-145) ppm is assigned to aromatic carbon, that at (150-190) ppm include phenolic and carboxylic carbons [15-17].

When we examine FTIR and ${ }^{13} \mathrm{C}$ NMR spectra of HA and INaA we observe that there is a decrease at the intensities of aliphatic alkyl groups, $-\mathrm{COOH}$ group and phenolic groups. The effect caus-

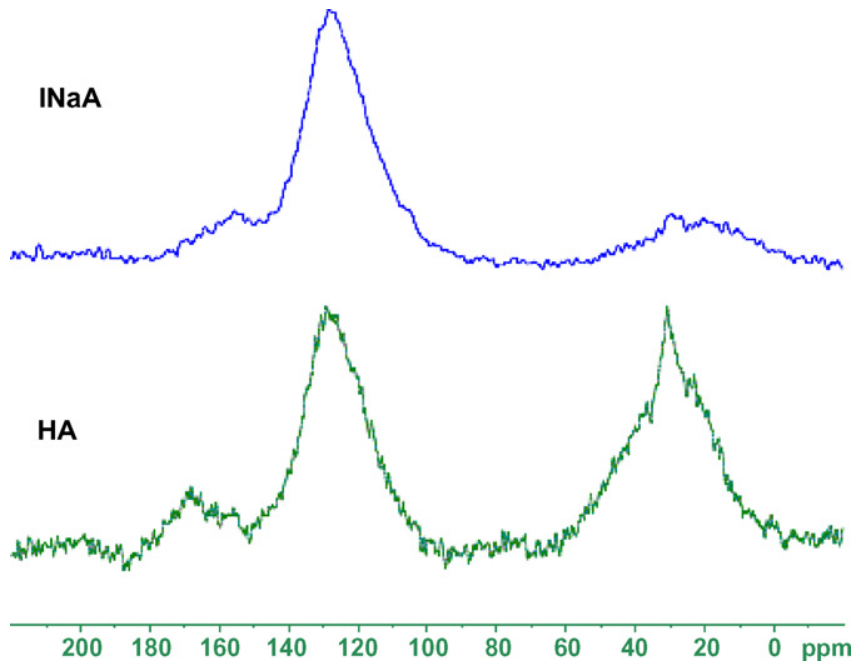

Fig. 4. ${ }^{13} \mathrm{C}$ NMR spectra of humic acid and sodium form of insolubilized humic acid. 


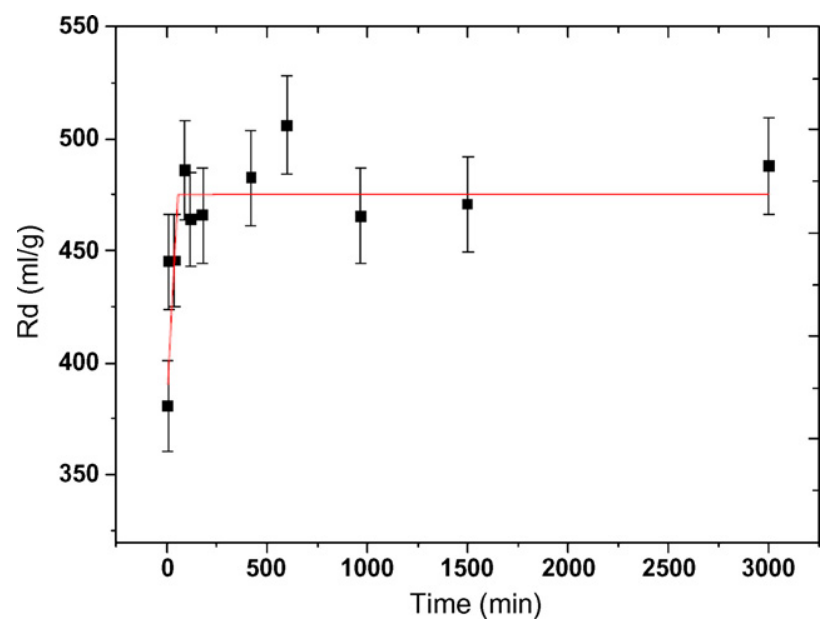

Fig. 5. Variation of $R_{\mathrm{d}}$ values with shaking time for $\mathrm{Cs}^{+}$sorption onto sodium form of insolubilized humic acid at an initial concentration of $1 \times 10^{-4} \mathrm{M}$ at $25^{\circ} \mathrm{C}$.

ing insolubilization is mainly due to loss in carboxyl groups, but as we see on spectrum, not all of the adsorption sites are lost during insolubilization. By this way, the ability of HA to make hydrogen bonding decreased and that caused the insolubilization of HA in water at high $\mathrm{pH}$ values. It is also clear from the ${ }^{13} \mathrm{C}$ NMR that aromatic part of HA is not affected after insolubilization, because there is no intensity change.

\subsection{Kinetic studies}

The experimental data in adsorption are expressed in terms of the distribution ratio, $R_{\mathrm{d}}$, defined as the ratio of adsorbate concentration on solid phase to its concentration in liquid phase. The distribution ratio of adsorption is defined as

$R_{\mathrm{d}}=\frac{[C]_{\text {solid }}}{[C]_{\text {liquid }}}$

where $[C]_{\text {solid }}(\mathrm{mmol} / \mathrm{g})$ and $[C]_{\text {liquid }}(\mathrm{mmol} / \mathrm{ml})$ are the concentrations of species $C$ in the solid and liquid phases, respectively. At the beginning of the sorption step, $V(\mathrm{ml})$ of solution with initial concentration $[\mathrm{C}]^{\circ}(\mathrm{mmol} / \mathrm{ml})$ is used and at the end of the sorption step $V(\mathrm{ml})$ of solution with concentration $[C]_{\text {liquid }}$ are present, hence the concentration of $C$ in the solid phase after sorption can be expressed as

$[C]_{\text {solid }}=\frac{V\left([C]^{\circ}-[C]_{\text {liquid }}\right)}{W_{\text {solid }}}$

In terms of radioactivity, $[C]_{\text {liquid }}$ can be written as

$[C]_{\text {liquid }}=\frac{A_{\text {liquid }}}{A^{\circ}}[C]^{\circ}$

From (2) to (4), the following equation is obtained:

$R_{\mathrm{d}}=\frac{V A^{\circ}-V A_{\text {liquid }}}{A_{\text {liquid }} W_{\text {solid }}}$

where $A^{\circ}$ is the initial count rate of solution added for sorption (cps) $/ \mathrm{ml}, A_{\text {liquid }}$ is the count rate of solution after sorption (cps) $/ \mathrm{ml}$, $W_{\text {solid }}$ is the weight of solid material (g) [23].

The sorption kinetics of $\mathrm{Cs}^{+}$and $\mathrm{Ba}^{2+}$ ions on INaA (sodium form of insolubilized humic acid) were examined by radioactive tracer method to determine the time required to reach equilibrium, rate constants and the nature of the kinetic model for each sorption process. The results of the variation of $R_{\mathrm{d}}$ as a function of time for $\mathrm{Cs}^{+}$ and $\mathrm{Ba}^{2+}$ ions on INaA are given in Figs. 5 and 6 and in Tables 1 and 2.

The sorption studies of $\mathrm{Cs}^{+}$and $\mathrm{Ba}^{2+}$ ions on INaA as a function of time were performed for time intervals ranging from 5 min up to

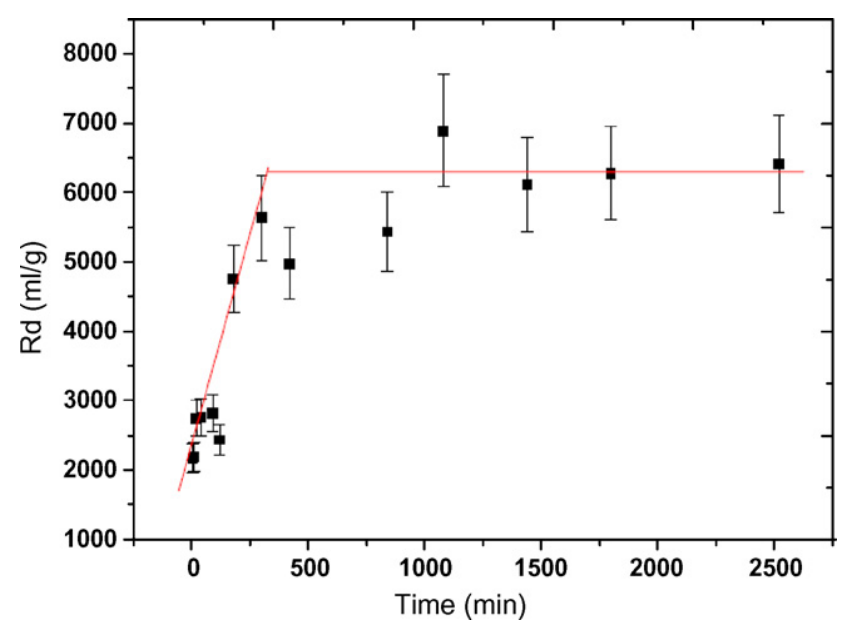

Fig. 6. Variation of $R_{\mathrm{d}}$ values with shaking time for $\mathrm{Ba}^{2+}$ sorption onto sodium form of insolubilized humic acid at an initial concentration of $1 \times 10^{-4} \mathrm{M}$ at $25^{\circ} \mathrm{C}$.

Table 1

The sorption data for the kinetic behavior $\mathrm{Cs}^{+}$ion onto sodium form of insolubilized humic acid at an initial concentration of $1 \times 10^{-4} \mathrm{M}$.

\begin{tabular}{rlllr}
\hline Time $(\mathrm{min})$ & $R_{\mathrm{d}}(\mathrm{ml} / \mathrm{g})$ & {$[\mathrm{Cs}]_{\text {liquid }}(\mathrm{mmol} / \mathrm{ml})$} & {$[\mathrm{Cs}]_{\text {solid }}(\mathrm{mmol} / \mathrm{g})$} & $t / q$ \\
\hline 5 & 381 & $6.63 \times 10^{-5}$ & 0.0252 & 198 \\
10 & 445 & $6.27 \times 10^{-5}$ & 0.0279 & 358 \\
40 & 446 & $6.27 \times 10^{-5}$ & 0.0279 & 1431 \\
90 & 486 & $6.07 \times 10^{-5}$ & 0.0295 & 3052 \\
120 & 464 & $6.18 \times 10^{-5}$ & 0.0287 & 4186 \\
180 & 466 & $6.17 \times 10^{-5}$ & 0.0287 & 6264 \\
420 & 482 & $6.08 \times 10^{-5}$ & 0.0294 & 14,306 \\
600 & 506 & $5.97 \times 10^{-5}$ & 0.0302 & 19,857 \\
966 & 465 & $6.17 \times 10^{-5}$ & 0.0287 & 33,634 \\
1500 & 471 & $6.14 \times 10^{-5}$ & 0.0289 & 51,869 \\
3000 & 488 & $6.06 \times 10^{-5}$ & 0.0295 & 101,514 \\
\hline
\end{tabular}

$48 \mathrm{~h}$. Equilibrium is reached after several hours of contact. Such a rapid process indicates that sorption is primarily a surface phenomena and the humic acid surface is readily accessible for ions from solution. On the basis of the obtained results an equilibrium period of 1 day was selected as a fixed parameter for further experiments, where the effects of loading and temperature, were examined.

Kinetic studies were also used to determine best fitting rate equations and rate constants of cation sorption. Azizian [7] has published kinetic models for the sorption behavior of solutes onto adsorbent and in his study, it has been shown that at low initial concentrations, the mechanism obeys pseudo second order model.

Table 2

The sorption data for the kinetic behavior $\mathrm{Ba}^{2+}$ ion on sodium form of insolubilized humic acid at an initial concentration of $1 \times 10^{(4)} \mathrm{M}$.

\begin{tabular}{rlllr}
\hline Time $(\mathrm{min})$ & $R_{\mathrm{d}}(\mathrm{ml} / \mathrm{g})$ & {$[\mathrm{Ba}]_{\text {liquid }}(\mathrm{mmol} / \mathrm{ml})$} & {$[\mathrm{Ba}]_{\text {solid }}(\mathrm{mmol} / \mathrm{g})$} & $t / q$ \\
\hline 5 & 2177 & $4.53 \times 10^{-5}$ & 0.0985 & 51 \\
10 & 2190 & $4.51 \times 10^{-5}$ & 0.0988 & 101 \\
20 & 2749 & $3.96 \times 10^{-5}$ & 0.1088 & 184 \\
40 & 2766 & $3.94 \times 10^{-5}$ & 0.1090 & 367 \\
90 & 2825 & $3.89 \times 10^{-5}$ & 0.1099 & 818 \\
120 & 2439 & $4.25 \times 10^{-5}$ & 0.1036 & 1159 \\
180 & 4755 & $2.75 \times 10^{-5}$ & 0.1306 & 1378 \\
300 & 5636 & $2.42 \times 10^{-5}$ & 0.1364 & 2199 \\
420 & 4978 & $2.66 \times 10^{-5}$ & 0.1322 & 3177 \\
840 & 5436 & $2.49 \times 10^{-5}$ & 0.1352 & 6212 \\
1080 & 6890 & $2.07 \times 10^{-5}$ & 0.1427 & 7567 \\
1440 & 6116 & $2.27 \times 10^{-5}$ & 0.1391 & 10,354 \\
1800 & 6280 & $2.23 \times 10^{-5}$ & 0.1399 & 12,866 \\
2520 & 6415 & $2.19 \times 10^{-5}$ & 0.1406 & 17,928 \\
\hline
\end{tabular}


Table 3

Amount of sorbed cation per gram of sorbent at equilibium, pseudo second order rate constants and correlation coefficient values for cesium and barium sorption.

\begin{tabular}{lcll}
\hline Sorbed cations & $q_{\mathrm{e}}(\mathrm{mol} / \mathrm{g})$ & $k_{2}\left(\mathrm{~g} \mathrm{~mol}^{-1} \mathrm{~min}^{-1}\right)$ & $R^{2}$ \\
\hline $\mathrm{Cs}^{+}$ & $29.44 \times 10^{(3}$ & 9.99 & 0.99 \\
$\mathrm{Ba}^{2+}$ & $141.30 \times 10^{(3}$ & 0.43 & 0.99 \\
\hline
\end{tabular}

The rate law for such a system is expressed as

$\frac{\mathrm{d} q}{\mathrm{~d} t}=k_{2}\left(q_{\mathrm{e}}-q\right)^{2}$

where $q$ and $q_{\mathrm{e}}$ are the amount of solute sorbed per gram of sorbent at any time and at equilibrium, respectively, and $k_{2}$ is the pseudo second order rate constant of sorption. After integration and rearrangement of the above equation, the following equation is obtained with a linear form

$\frac{t}{q}=\frac{1}{k_{2} q_{\mathrm{e}}^{2}}+\frac{1}{q_{\mathrm{e}}} t$

The plot of $t / q$ versus $t$ gives a straight line with slope of $1 / q_{\mathrm{e}}$ and intercept of $1 / k_{2} q_{\mathrm{e}}^{2}$. So the amount of cation sorbed per gram of sorbent (INaA) at equilibrium $q_{\mathrm{e}}$ and sorption rate constant $k_{2}$ could be evaluated from the slope and intercept, respectively. The results obtained are shown in Table 3 and in Figs. 7 and 8.

It is apparent from $q_{\mathrm{e}}$ values that barium ions are sorbed five times more than cesium ions and rate constant values show that

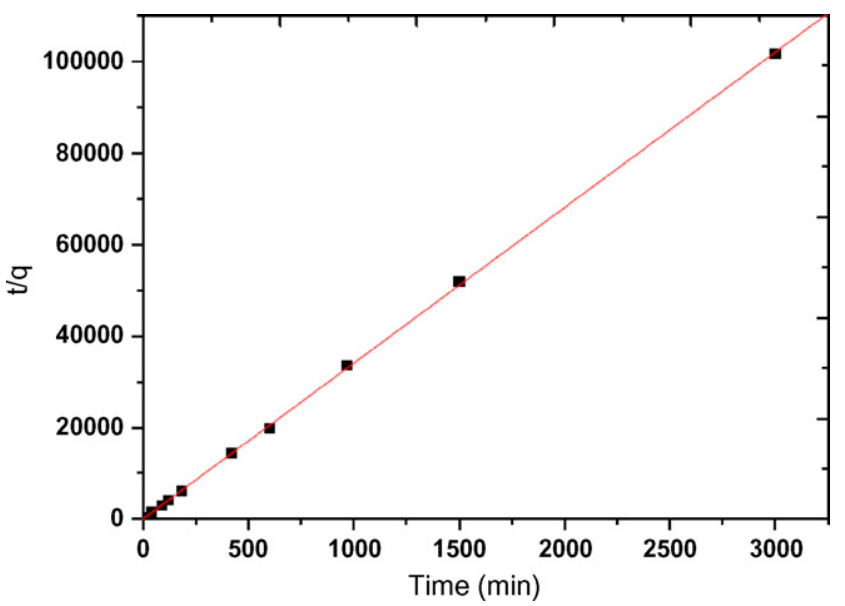

Fig. 7. Variation of $t / q$ values with shaking time for $\mathrm{Cs}^{+}$sorption on sodium form of insolubilized humic acid at $25^{\circ} \mathrm{C}$.

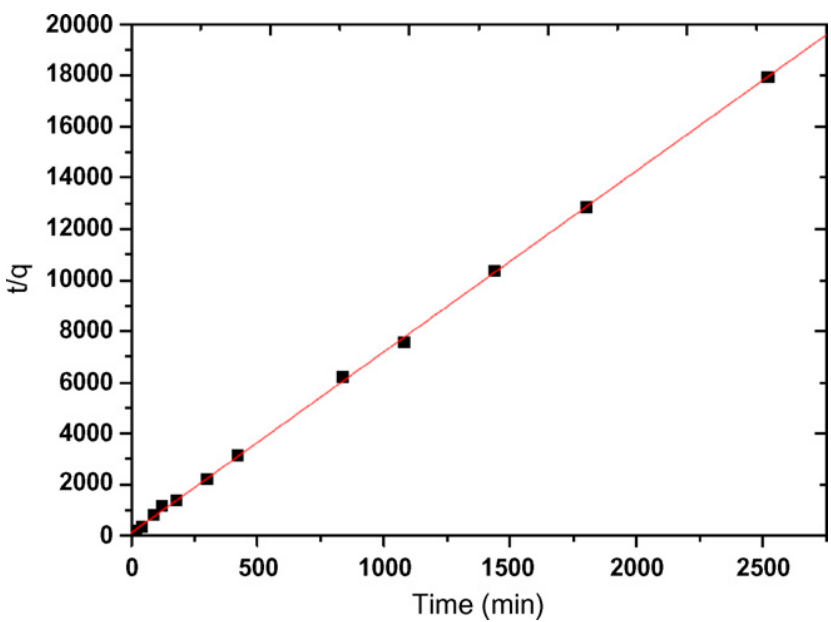

Fig. 8. Variation of $t / q$ values with shaking time for $\mathrm{Ba}^{2+}$ sorption on sodium form of insolubilized humic acid at $25^{\circ} \mathrm{C}$.

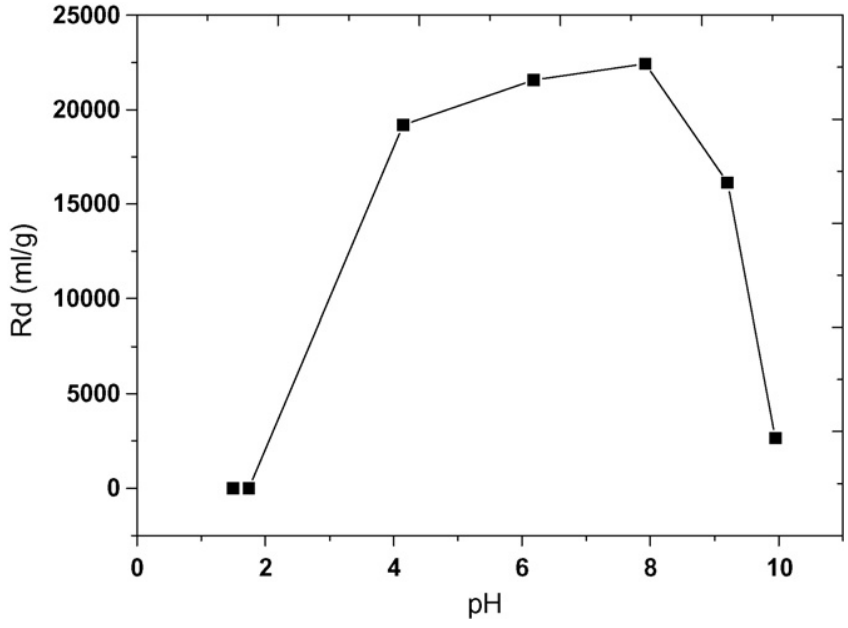

Fig. 9. Effect of $\mathrm{pH}$ upon sorption of $\mathrm{Ba}^{2+}$ onto sodium form of insolubilized humic acid at $25^{\circ} \mathrm{C}$.

cesium is much more rapidly adsorbed by INaA. Correlation coefficient values indicate that pseudo second order rate equation completely fits the sorption behavior of low concentrations of cesium and barium ions onto INaA.

The less sorption tendency of cesium ions onto INaA can be explained by its charge. An increase in the oxidation state favors the accumulation of these ions on the sorption surface leading to electrostatic neutrality.

\subsection{Effect of $\mathrm{pH}$ upon cation sorption}

The increase of $\mathrm{pH}$ value has a substantial effect upon sorption of $\mathrm{Ba}^{2+}$ onto INaA, as shown in Fig. 9. The experiment was carried out using $10 \mathrm{mg}$ of INaA as sorbent, $9 \mathrm{ml}$ of $1 \times 10^{-5} \mathrm{M}$ of $\mathrm{Ba}^{2+}$ solution with varying $\mathrm{pH}$ values. It is seen that there is almost no adsorption between $\mathrm{pH}(1-2)$ range. In the literature $[5,8]$ it is also emphasized that in aqueous media there is a competition between $\mathrm{H}_{3} \mathrm{O}^{+}$ and metal ions toward the solid phase. At low pHs, the surface of the adsorbent is closely associated with the hydronium ions and repulsive forces limit the approach of the metal ions. As we increase the $\mathrm{pH}$, we observe a dramatic increase of the uptake of $\mathrm{Ba}^{2+}$ by INaA, because the principal adsorption sites $-\mathrm{COOH}$ and $-\mathrm{COH}$ dissociate to their anionic forms $-\mathrm{COO}^{-}$and $-\mathrm{CO}^{-}$. These dissociations cause negatively charged surfaces and cations could more easily adsorb onto the solid surface. At pH value beyond 8 , we observe a sharp decrease at sorption capacity of sorbent. One possible explanation may be the formation of hydrolysed or barium carbonate complexes. In the case of $\mathrm{Cs}^{+}$sorption, we also expect an increased uptake of $\mathrm{Cs}^{+}$to the humic acid surface as the $\mathrm{pH}$ increases, but not as much as the uptake of barium ions, because of weaker interaction of $\mathrm{Cs}^{+}$ions with humic acid surface when compared to the interaction between $\mathrm{Ba}^{2+}$ ions and humic acid surface.

\subsection{Freundlich isotherm}

Freundlich isotherm model [3] is one of the most used non-linear model for describing the dependence of sorption on sorbate concentration. This model allows for several kinds of sorption sites on solid and represents properly the sorption data at low and intermediate concentrations on heterogeneous surfaces. The general expression of Freundlich isotherm is given as

$[C]_{\text {solid }}=k[C]_{\text {liquid }}^{n}$

where $[C]_{\text {solid }}$ is the amount of ionic species adsorbed on the solid matrix at equilibrium $(\mathrm{mmol} / \mathrm{g}),[C]_{\text {liquid }}$ is the concentration of the 
Table 4

The data of $\mathrm{Cs}^{+}$sorption onto sodium form of insolubilized humic acid at different temperatures and initial concentrations.

\begin{tabular}{llrll}
\hline Temp. $(\mathrm{K})$ & {$[\mathrm{C}]^{\circ}(\mathrm{mmol} / \mathrm{ml})$} & $R_{\mathrm{d}}(\mathrm{ml} / \mathrm{g})$ & {$[\mathrm{Cs}]_{\mathrm{s}}(\mathrm{mmol} / \mathrm{g})$} & {$[\mathrm{Cs}]_{\text {liq }}(\mathrm{mmol} / \mathrm{ml})$} \\
\hline $\mathbf{2 8 8}$ & $\mathbf{1} \times \mathbf{1 0}^{-2}$ & $\mathbf{4 8}$ & $\mathbf{0 . 4 4 9}$ & $\mathbf{9 . 4} \times \mathbf{1 0}^{-3}$ \\
288 & $5 \times 10^{-4}$ & 454 & 0.141 & $3.11 \times 10^{-4}$ \\
288 & $1 \times 10^{-4}$ & 4548 & 0.0644 & $1.41 \times 10^{-5}$ \\
288 & $1 \times 10^{-5}$ & 9849 & 0.00697 & $7.08 \times 10^{-7}$ \\
288 & $5 \times 10^{-6}$ & 10,984 & 0.00351 & $3.20 \times 10^{-7}$ \\
$\mathbf{2 9 8}$ & $\mathbf{1} \times \mathbf{1 0}^{-2}$ & $\mathbf{1 1 9}$ & $\mathbf{1 . 0 2 8}$ & $\mathbf{8 . 6 3} \times \mathbf{1 0}^{-3}$ \\
298 & $5 \times 10^{-4}$ & 507 & 0.151 & $2.98 \times 10^{-4}$ \\
298 & $1 \times 10^{-4}$ & 3894 & 0.0629 & $1.61 \times 10^{-5}$ \\
298 & $1 \times 10^{-3}$ & 10,554 & 0.00700 & $6.63 \times 10^{-7}$ \\
298 & $5 \times 10^{-6}$ & 11,343 & 0.00352 & $3.10 \times 10^{-7}$ \\
$\mathbf{3 0 8}$ & $\mathbf{1} \times \mathbf{1 0}^{-2}$ & $\mathbf{5 2}$ & $\mathbf{0 . 4 9 1}$ & $\mathbf{9 . 3 5} \times \mathbf{1 0}^{-3}$ \\
308 & $5 \times 10^{-4}$ & 405 & 0.131 & $3.25 \times 10^{-4}$ \\
308 & $1 \times 10^{-4}$ & 2810 & 0.0592 & $2.11 \times 10^{-5}$ \\
308 & $1 \times 10^{-5}$ & 10,693 & 0.00701 & $6.55 \times 10^{-7}$ \\
308 & $5 \times 10^{-6}$ & 12,591 & 0.00354 & $2.81 \times 10^{-7}$ \\
$\mathbf{3 1 8}$ & $\mathbf{1} \times \mathbf{1 0}^{-2}$ & $\mathbf{4 2}$ & $\mathbf{0 . 3 9 8}$ & $\mathbf{9 . 4 7} \times \mathbf{1 0}^{-3}$ \\
318 & $5 \times 10^{-4}$ & 332 & 0.115 & $3.46 \times 10^{-4}$ \\
318 & $1 \times 10^{-4}$ & 2675 & 0.0586 & $2.19 \times 10^{-5}$ \\
318 & $1 \times 10^{-11}$ & 11,372 & 0.00704 & $6.19 \times 10^{-7}$ \\
318 & $5 \times 10^{-6}$ & 12,416 & 0.00354 & $2.85 \times 10^{-7}$ \\
\hline
\end{tabular}

cation in solution at equilibrium ( $\mathrm{mmol} / \mathrm{ml}), k$ and $n$, are Freundlich constants.

This expression can be linearized as

$\log [C]_{\text {solid }}=\log k+n \log [C]_{\text {liquid }}$

Plotting $\log [C]_{\text {solid }}$ versus $\log [C]_{\text {liquid }}$ yields " $n$ " as the slope and "log $k$ " as the intercept.

The data of sorption of $\mathrm{Cs}^{+}$and $\mathrm{Ba}^{2+}$ onto INaA at different temperatures and initial concentrations are given in Tables 4 and 5 . The Freundlich isotherm plots for cesium and barium ions at different loadings and temperatures on INaA are shown in Figs. 10 and 11 and the Freundlich constants $n$ and $k$ obtained for different sorption cases are given in Table 6.

The values of ' $n$ ' being less than 1.0 in all cases indicate a nonlinear sorption that takes place on a heterogeneous surface. The non-linearity indicates that the sorption energy barrier increases exponentially as the fraction of occupied sites on sorbent increases. Increase of temperature $\left(40^{\circ} \mathrm{C}\right)$ has no pronounced effect on " $n$ " values for the sorption of these cations onto INaA.

The magnitude of " $k$ " is related to sorption affinity. When we use INaA as a sorbent, we found that there is a significant difference between " $k$ " values for the sorption behavior of cesium and barium ions. This clearly indicates that INaA has a much higher tendency to adsorb barium ions compared with cesium ions. This is in line with the observed lower $R_{\mathrm{d}}$ values of $\mathrm{Cs}^{+}$sorption.

Table 5

The data of $\mathrm{Ba}^{2+}$ sorption onto sodium form of insolubilized humic acid at different temperatures and initial concentrations.

\begin{tabular}{llrll}
\hline Temp. $(\mathrm{K})$ & {$[\mathrm{C}]^{\circ}(\mathrm{mmol} / \mathrm{ml})$} & $R_{\mathrm{d}}(\mathrm{ml} / \mathrm{g})$ & {$[\mathrm{Ba}]_{\mathrm{s}}(\mathrm{mmol} / \mathrm{g})$} & {$[\mathrm{Ba}]_{\mathrm{liq}}(\mathrm{mmol} / \mathrm{ml})$} \\
\hline $\mathbf{2 9 8}$ & $\mathbf{1} \times \mathbf{1 0}^{-\mathbf{4}}$ & $\mathbf{7 4 4 6}$ & $\mathbf{0 . 1 4 5}$ & $\mathbf{1 . 9 5} \times \mathbf{1 0}^{-\mathbf{5}}$ \\
298 & $1 \times 10^{-5}$ & 18,065 & 0.0164 & $9.06 \times 10^{-7}$ \\
298 & $5 \times 10^{-6}$ & 26,153 & 0.00842 & $3.22 \times 10^{-7}$ \\
298 & $1 \times 10^{-6}$ & 58,874 & 0.00175 & $2.97 \times 10^{-8}$ \\
$\mathbf{3 0 8}$ & $\mathbf{1} \times \mathbf{1 0}^{-4}$ & $\mathbf{8 2 7 5}$ & $\mathbf{0 . 1 4 8}$ & $\mathbf{1 . 7 9} \times \mathbf{1 0}^{-5}$ \\
308 & $1 \times 1^{-5}$ & 22,938 & 0.0167 & $7.28 \times 10^{-7}$ \\
308 & $5 \times 10^{-6}$ & 32,368 & 0.00853 & $2.63 \times 10^{-7}$ \\
308 & $1 \times 10^{-6}$ & 27,026 & - & - \\
$\mathbf{3 1 8}$ & $\mathbf{1} \times \mathbf{1 0}^{-4}$ & $\mathbf{6 4 3 9}$ & $\mathbf{0 . 1 4 1}$ & $\mathbf{2 . 1 8} \times \mathbf{1 0}^{-5}$ \\
318 & $1 \times 10^{-5}$ & 23,292 & 0.0167 & $7.17 \times 10^{-7}$ \\
318 & $5 \times 10^{-6}$ & 26,522 & 0.00843 & $3.18 \times 10^{-7}$ \\
318 & $1 \times 10^{-6}$ & 37,487 & 0.00172 & $4.58 \times 10^{-8}$ \\
$\mathbf{3 2 8}$ & $\mathbf{1} \times \mathbf{1 0}^{-4}$ & $\mathbf{6 8 9 6}$ & $\mathbf{0 . 1 4 3}$ & $\mathbf{2 . 0 7} \times \mathbf{1 0}^{-5}$ \\
328 & $5 \times 10^{-6}$ & 38,156 & 0.00859 & $2.25 \times 10^{-7}$ \\
328 & $1 \times 10^{-6}$ & 43,284 & 0.00173 & $3.99 \times 10^{-8}$
\end{tabular}

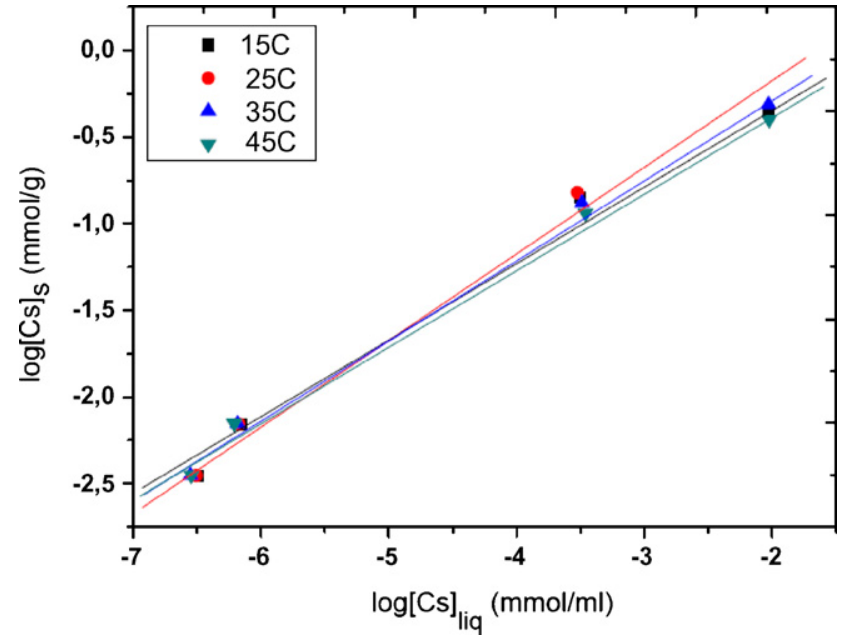

Fig. 10. Freundlich isotherm plots for the sorption of $\mathrm{Cs}^{+}$onto sodium form of insolubilized humic acid at various temperatures using $10 \mathrm{mg}$ sorbent.

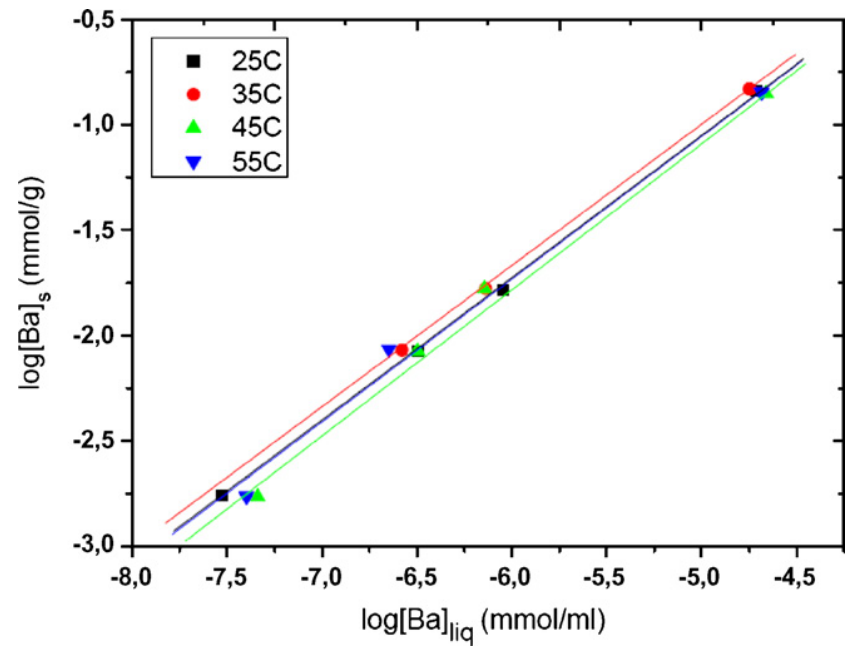

Fig. 11. Freundlich isotherm plots for the sorption of $\mathrm{Ba}^{2+}$ onto sodium form of insolubilized humic acid at various temperatures using $5 \mathrm{mg}$ sorbent.

\subsection{Dubinin-Radushkevich isotherms}

The D-R isotherm model ${ }^{20}$ is valid at low concentration ranges and can be used to describe sorption on both homogeneous and heterogeneous surfaces. It can be represented by the general expression:

$[C]_{\text {solid }}=[C]_{m} \exp -\left(K \varepsilon^{2}\right)$

Table 6

Freundlich constants, $n$ and $k$, obtained from the least square fits of the sorption data of $\mathrm{Cs}^{+}$and $\mathrm{Ba}^{2+}$ onto sodium form of insolubilized humic acid.

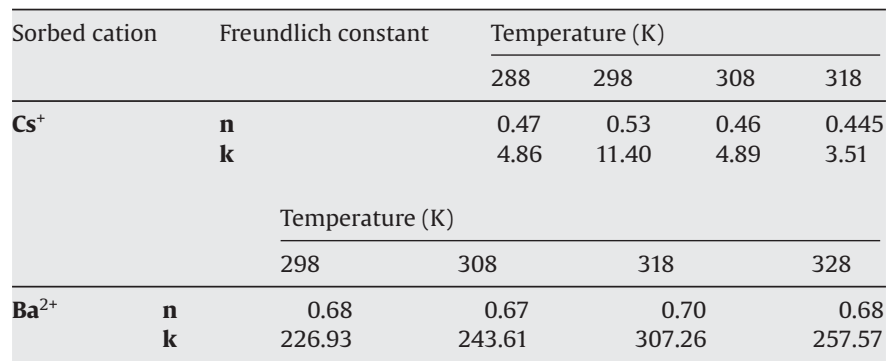

The linear correlation coefficients were all greater than 0.99 . 


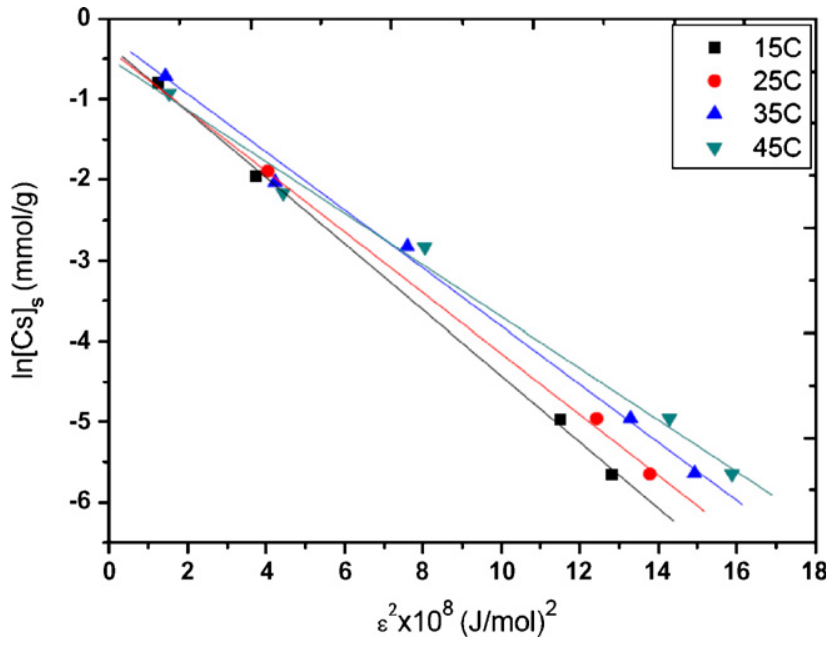

Fig. 12. Dubinin-Raduskevich isotherm plots for sorption of $\mathrm{Cs}^{+}$onto sodium form of insolubilized humic acid at various temperatures using $10 \mathrm{mg}$ sorbent.

where $\varepsilon$ Polanyi potential, $R T \ln \left(1+1 / C_{\text {liquid }}\right), C_{\text {liquid }}$ is the solute equilibrium constant in solution $(\mathrm{mmol} / \mathrm{ml}), R$ is the ideal gas constant $\left(8.3145 \mathrm{~J} \mathrm{~mol}^{-1} \mathrm{~K}^{-1}\right), T$ is the absolute temperature $(\mathrm{K}),[C]_{m}$ is the sorption capacity of sorbent per unit weight ( $\mathrm{mmol} / \mathrm{g}), K$ is the constant related to the energy of sorption, $[C]_{\text {solid }}$ is the amount of solute sorbed per unit weight $(\mathrm{mmol} / \mathrm{g})$.

The linear form of the equation above can be obtained by rearranging it to give

$\ln C_{\text {solid }}=\ln C_{m}-K \varepsilon^{2}$

If $\ln C_{\text {solid }}$ is plotted against $\varepsilon^{2}, K$ and $\ln C_{m}$ will be obtained from the slope and the intercept, respectively. The value of $K(\mathrm{~mol} / \mathrm{kJ})$ [2] is related to the adsorption mean free energy, $E(\mathrm{~kJ} / \mathrm{mol})$, defined as the free energy change required to transfer 1 mole of ions from infinity in solution to the solid surface. The adsorption mean free energy $E$ is given as

$E=(2 K)^{-1 / 2}$

Sorption of $\mathrm{Cs}^{+}$and $\mathrm{Ba}^{2+}$ onto INaA fitted the D-R model well as shown in Figs. 12 and 13 and the corresponding values of $C_{m}, K$ and $E$ are given in Table 7. $C_{m}$ values indicate that barium ions are sorbed 5 times more than $\mathrm{Cs}^{+}$ions and decrease with increasing temperature, but changes are not significant. The affinity of a cation for ion-exchange sites is a function of the charge and size of the cation. Cesium ion sorption results showed lower sorption affinity onto INaA compared to barium ion, because of the higher charge density of barium leading to stronger sorption complexes.

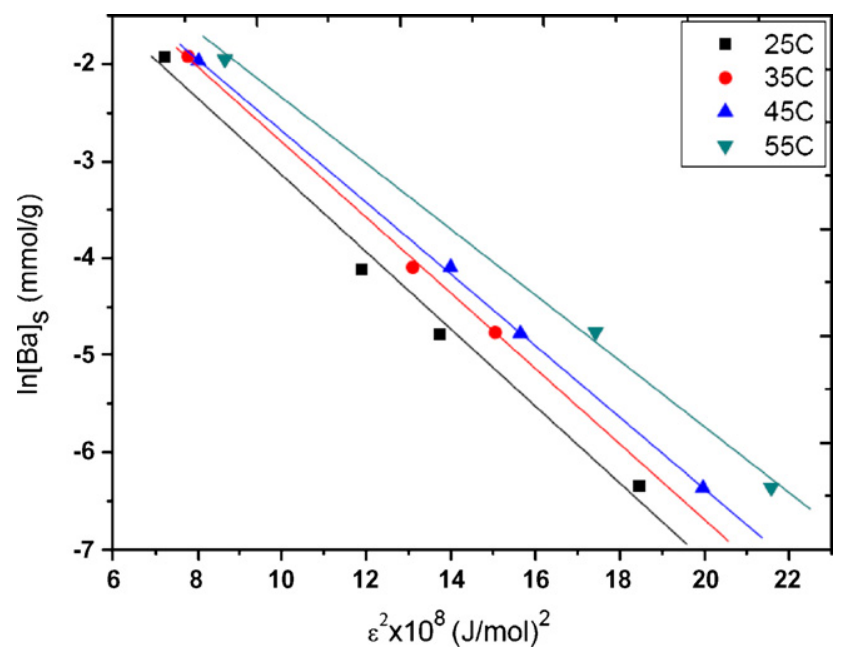

Fig. 13. Dubinin-Raduskevich isotherm plots for sorption of $\mathrm{Ba}^{2+}$ onto sodium form of insolubilized humic acid at various temperatures using $5 \mathrm{mg}$ sorbent.

In all cases, the mean free energy of sorption, $E$, is in $8-16 \mathrm{~kJ} / \mathrm{mol}$ energy range corresponding to ion-exchange type of sorption [18].

\subsection{Thermodynamic results}

The values of $\Delta H^{\circ}$ and $\Delta S^{\circ}$ of $\mathrm{Cs}^{+}$and $\mathrm{Ba}^{2+}$ sorption were obtained by fitting the experimental data to equation (12) which is deduced from Gibbs free energy change equation (13).

$\ln R_{\mathrm{d}}=\frac{\Delta S^{\circ}}{R}=\frac{\Delta H^{\circ}}{R T}$

$\Delta G^{\circ}=\Delta H^{\circ}-T \Delta S^{\circ}$

$\Delta H^{\circ}$ and $\Delta S^{\circ}$ values are dependent only on the temperature and pressure, therefore no concentration dependence is expected. Different $R_{\mathrm{d}}$ values are obtained at different loadings (initial concentrations of a particular cation). Therefore, distribution ratio, $R_{\mathrm{d}}$, in Eq. (10) is an empirical equilibrium constant that is valid at a particular initial concentration and reaction conditions. This difficulty associated with the description of sorption data which is the lack of a thermodynamic equilibrium constant over a wide range of concentrations can be partially overcome by applying empirical distribution constants. In order to obtain values of these thermodynamic constants that are representative over the entire concentration ranges, averaged $\Delta H^{\circ}$ and $\Delta S^{\circ}$ values of different sorption cases were calculated. Consequently, an assumption is made in which the fluctuations in the $\Delta H^{\circ}$ and $\Delta S^{\circ}$ values are small enough to calculate the average of these values at different concentrations [21].

Table 7

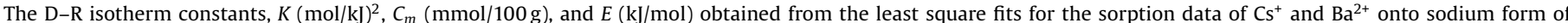
insolubilized humic acid.

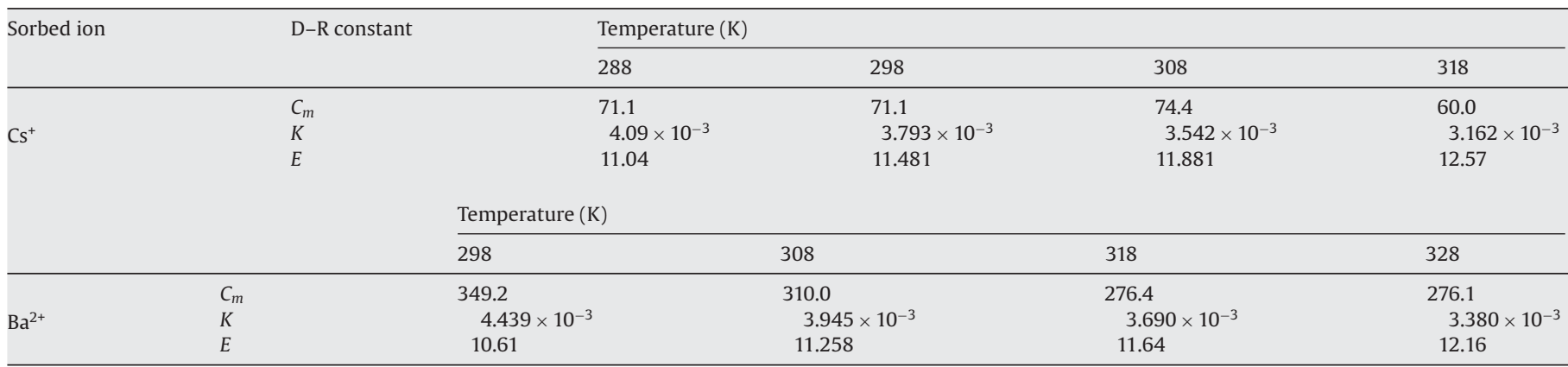

The linear correlation coefficients were all greater than 0.99 . 
Table 8

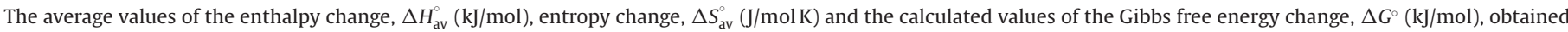
at different temperatures for the sorption case of $\mathrm{Cs}^{+}$and $\mathrm{Ba}^{2+}$ onto sodium form of insolubilized humic acid.

\begin{tabular}{|c|c|c|c|c|c|c|c|}
\hline \multirow[t]{2}{*}{ Sorbed ion } & \multirow[t]{2}{*}{$\Delta H_{\mathrm{av}}^{\circ}(\mathrm{kJ} / \mathrm{mol})$} & \multirow[t]{2}{*}{$\Delta S_{\mathrm{av}}^{\circ}(\mathrm{J} / \mathrm{mol} \mathrm{K})$} & & \multicolumn{4}{|c|}{$\Delta G^{\circ}(\mathrm{kJ} / \mathrm{mol})$ at different temperatures $(\mathrm{K})$} \\
\hline & & & & 288 & 298 & 308 & 318 \\
\hline \multirow[t]{3}{*}{$\mathrm{Cs}^{+}$} & -3.67 & 48.85 & & -17.74 & -18.23 & -18.72 & -19.21 \\
\hline & & & \multicolumn{5}{|c|}{$\Delta G^{\circ}(\mathrm{kJ} / \mathrm{mol})$ at different temperatures $(\mathrm{K})$} \\
\hline & & & 298 & & 308 & 318 & 328 \\
\hline $\mathrm{Ba}^{2+}$ & 2.10 & 89.522 & -24.57 & & -25.47 & -26.36 & -27.26 \\
\hline
\end{tabular}

The results are given in Table 8 . Average values for $\Delta H$ and $\Delta S$ at different temperatures were taken. The average $\Delta H^{\circ}$ values for $\mathrm{Cs}^{+}$and $\mathrm{Ba}^{2+}$ sorption onto INaA indicate that sorption of $\mathrm{Cs}^{+}$ onto INaA is exothermic, $\mathrm{Ba}^{2+}$, endothermic. In liquid-solid systems, when temperature is increased, the behavior of ions in solution or on the solid will be subject to factors such as the interionic forces, the hydration energy, the availability of sorption sites and the relative stability of sorbed ions at these sites [19]. Exothermic behavior of $\mathrm{Cs}^{+}$ion sorption onto INaA can be explained by the thermal destabilization leading to an increase in the mobility of cesium ions on the surface of the solid as the temperature is increased, thus enhancing desorption. Positive $\Delta H^{\circ}$ value was obtained for $\mathrm{Ba}^{2+}$ sorption onto InaA. There is a large difference in hydration enthalpies, being $-276 \mathrm{~kJ} / \mathrm{mol}$ for $\mathrm{Cs}^{+}$and $-1305 \mathrm{~kJ} / \mathrm{mol}$ for $\mathrm{Ba}^{2+}$ ions. In the literature [20], it is reported that metal ions with high hydration energies are well solvated in water and for cations that are solvated well in water, sorption requires that such ions should be stripped to a certain extent of their hydration shell which is a process that requires energy input. If this dehydration energy exceeds the exothermicity associated with the sorption of a metal ion on a solid, then the overall energy balance will lead to an endothermic behavior.

Generally, it is expected that the entropy change of the system would be negative at the end of the sorption reaction due to transferring the sorbate ions from a disordered state in solution to a more ordered state when fixed by sorbent. However, there are some other factors which should be considered. One of them is the dehydration step that increases the mobility of ions and that of the surrounding water molecules in solution. The release of bound sodium ions from solid phase to the liquid phase is another reason, especially in the case of $\mathrm{Ba}^{2+}$ sorption where two monovalent ions of $\mathrm{Na}^{+}$is exchanged for each $\mathrm{Ba}^{2+}$ ions [21,22].

The calculated negative values of $\Delta G^{\circ}$ for all cases indicate that the sorption process of each is spontaneous and preferentially driven toward the products. Temperature change has no significant effect on $\Delta G^{\circ}$ values for both sorptions.

\section{Conclusions}

Insolubilized humic acid can be used as an effective adsorbent to remove radionuclides $\left(\mathrm{Cs}^{+}\right.$and $\mathrm{Ba}^{2+}$ ) from aquatic environments. Equilibrium in cation sorption is achieved within hours of contact between the solution of adsorbed cations and insolubilized humic acid indicating that fast sorption mechanisms are involved and the sorption process is mainly a surface phenomena.

Structural changes were determined using FTIR and ${ }^{13} \mathrm{C}$ NMR techniques during modification of humic acid. The amount of adsorption sites (carboxylic and phenolic groups) decreased during insolubilization step.

Kinetic studies indicated that adsorption behaviors of cations $\left(\mathrm{Cs}^{+}\right.$and $\left.\mathrm{Ba}^{2+}\right)$ obey pseudo second order rate law. Cation sorption data have been interpreted in terms of Freundlich and Dubinin-Radushkevich equations. There is an inverse relationship between the rate of sorption and the sorption order for the cation sorptions studied.

The $\mathrm{pH}$ experiments showed that insolubilized humic acid has a higher sorption capacity towards cations at high $\mathrm{pH}$ values, because of the dissociation of all acidic hydrogens.

The sorption data obtained at different temperatures indicate that cation sorption onto insolubilized humic acid is not affected significantly by the temperature change, whereas cation sorption onto iron nanoparticles is an exothermic process. Positive entropy values were found in the case of cation sorption onto insolubilized humic acid. Negative $\Delta G^{\circ}$ values in all cation sorption processes show that sorption process is spontaneous.

\section{References}

[1] T. Shahwan, H.N. Erten, Thermodynamic parameters of $\mathrm{Cs}^{+}$sorption on natural clays, J. Radioanal. Nucl. Chem. 253 (2002) 115-120.

[2] A.D. Ebner, J.A. Ritter, J.D. Navratil, Adsorption of cesium, strontium, and cobalt ions on magnetite and a magnetite-silica composite, Ind. Eng. Chem. Res. 40 (2001) 1615-1623.

[3] T. Shahwan, H.N. Erten, Temperature effects in barium sorption on natural kaolinite and chlorite-illite clays, J. Radioanal. Nucl. Chem. 260 (2004) 43-48.

[4] R. Sutton, G. Sposito, Molecular structure in soil humic substances: the new view, Environ. Sci. Technol. 39 (2005) 9009-9015.

[5] O. Gezici, H. Kara, M. Ersöz, Y. Abali, The sorption behavior of a nickelinsolubilized humic acid system in a column arrangement, J. Colloid Interface Sci. 292 (2005) 381-391.

[6] H. Seki, A. Suzuki, Adsorption of heavy metal ions onto insolubilized humic acid, J. Colloid Interface Sci. 171 (1995) 490-494.

[7] S. Azizian, Kinetic models of sorption: a theoretical analysis, J. Colloid Interface Sci. 276 (2004) 47-52.

[8] H. Baker, F. Khalili, Analysis of the removal of lead(II) from aqueous solutions by adsorption onto insolubilized humic acid: temperature and $\mathrm{pH}$ dependence, Anal. Chim. Acta 516 (2004) 179-186.

[9] B. El-Eswed, F. Khalili, Adsorption of $\mathrm{Cu}(\mathrm{II})$ and $\mathrm{Ni}(\mathrm{II})$ on solid humic acid from the Azraq area, Jordan, J. Colloid Interface Sci. 299 (2006) 497-503.

[10] J.C. Masini, G. Abate, E.C. Lima, L.C. Hahn, M.S. Nakamura, J. Lichtig, H.R Nagatomy, Comparison of methodologies for determination of carboxylic and phenolic groups in humic acids, Anal. Chim. Acta 364 (1998) 223-233.

[11] G. Gran, Determination of the equivalence point in potentiometric titrations, Analyst 77 (1952) 661

[12] V.M. Benites, E. Mendonca, C.E.G.R. Schaefer, E.H. Novotny, E.L. Reis, J.C. Ker Properties of black soil humic acids from high altitude rocky complexes in Brazil, Geoderma 127 (2005) 104-113.

[13] L.T. Shirshova, E.A. Ghabbour, G. Davies, Spectroscopic characterization of humic acid fractions isolated from soil using different extraction procedures, Geoderma 133 (2006) 204-216.

[14] D. Xu, S. Zhu, H. Chen, F. Li, Structural characterization of humic acids isolated from typical soils in China and their adsorption characteristics to phenanthrene, Colloid. Surf. A: Physicochem. Eng. Aspects 276 (2006) 1-7.

[15] M.J. Simpson, A.J. Simpson, P.G. Hatcher, Non-covalent associations between hydrophobic organic contaminants and dissolved organic material observed by NMR, Environ. Toxicol. Chem. 23 (2) (2004) 355-362.

[16] R.L. Cook, C. Langford, Structural characterization of a fulvic acid and humic acid using solid-state ramp-CP-MAS ${ }^{13} \mathrm{C}$ nuclear magnetic resonance, Environ. Sci. Technol. 32 (1998) 719-725.

[17] R. Frund, H.D. Ludemann, F.J. Gonzalez-Vila, G. Almendros, J.C. del Rio, F. Martin, Structural differences between humic fractions from different soil types as determined by FT-IR and ${ }^{13}$ C-NMR studies, Sci. Total Environ. 81/82 (1989) 187-194.

[18] F. Helferrich, Ion Exchange, McGraw Hill, New York, 1964

[19] T. Shahwan, H.N. Erten, S. Unugur, A characterization study of some aspects of the adsorption of aqueous $\mathrm{Co}^{2+}$ ions on a natural bentonite clay, J. Colloid Interface Sci. 300 (2006) 447-452. 
[20] D. Akar, T. Shahwan, A.E. Eroglu, Kinetic and thermodynamic investigations of strontium ions retention by natural kaolinite and clinoptilolite minerals, Radiochim. Acta 93 (2005) 477-485.

[21] T. Shahwan, Ph.D. Thesis, Department of Chemistry, Bilkent University, 2000.
[22] S.A. Khan, R.U. Reman, M.A. Khan, Adsorption of $\mathrm{Cs}(\mathrm{I}), \mathrm{Sr}(\mathrm{II})$ and $\mathrm{Co}(\mathrm{II})$ on $\mathrm{Al}_{2} \mathrm{O}_{3}$ J. Radioanal. Nucl. Chem. 190 (1995) 81.

[23] T. Shahwan, S. Suzer, H.N. Erten, Sorption studies of $\mathrm{Cs}^{+}$and $\mathrm{Ba}^{2+}$ cations on magnesite, Appl. Radiat. Isot. 49 (1998) 915-921. 